\title{
Hypertrophic Cardiomyopathy in Two Elderly Siblings
}

\author{
Kazuhiro Masuya, M.D., Eiji Murakami, M.D., \\ Noboru Takekoshi, M.D., Shinobu Matsur, M.D., \\ Hidenori Murakami, M.D., Masayuki Nomura, M.D., \\ Shizuka Fujita, M.D., Sotoyuki TsujI, M.D., \\ Takashi Chadani, M.D., Jiro Emoto, M.D., \\ Hiroichi Tsugawa, M.D., Akihisa Hashimoto, M.D., \\ and Isao Noumi, M.D.
}

\section{Summary}

Hypertrophic cardiomyopathy, which is sometimes familial and genetically transmitted as an autosomal dominant trait, is generally regarded as a disease of young or middle aged and relatively few cases have been reported in elderly patients. The present communication describes the oldest known siblings with clinically diagnosed hypertrophic cardiomyopathy, 80 and 78 years of age.

\section{Additional Indexing Words:}

Hypertrophic cardiomyopathy Elderly siblings Echocardiography

$\mathrm{H}^{2}$

YPERTROPHIC cardiomyopathy is not an uncommon disease, but, it is generally regarded as a disease of young or middle aged and relatively few cases have been reported in elderly patients. ${ }^{1)-8)}$ The present communication describes the oldest known siblings with clinically diagnosed hypertrophic cardiomyopathy.

\section{Case Reports}

Case 1; An 80-year-old woman was first admitted to the Inami-Kousei Hospital in June 1979, with low grade fever, cough, and fatigue. Her past history and precise family history were unremarkable, but she had never experienced episode of dyspnea, syncope, or angina and was not taking any cardiac medications. The physical examination on admission revealed a blood pressure of $126 / 66 \mathrm{mmHg}$, regular pulse at rate of 72 per minute, brisk-

From the Division of Cardiology, Department of Internal Medicine, Kanazawa Medical University, Uchinada-machi, Kahoku-gun, Ishikawa-ken 920-02, Japan.

Received for publication February 9, 1981. 


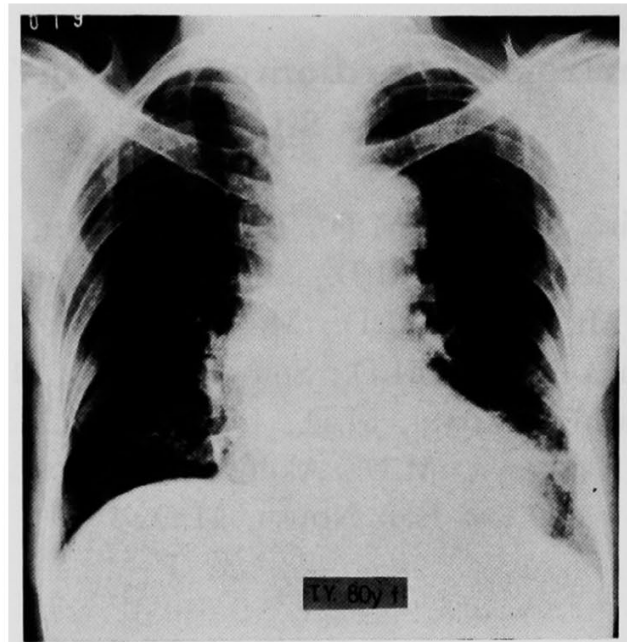

Fig. 1. Chest roentogenogram of Case 1 shows enlarged cardiac silhouette (cardiothoracic ratio: $63^{\circ}{ }_{0}$ ) and an infiltrate in the left lower lobe.
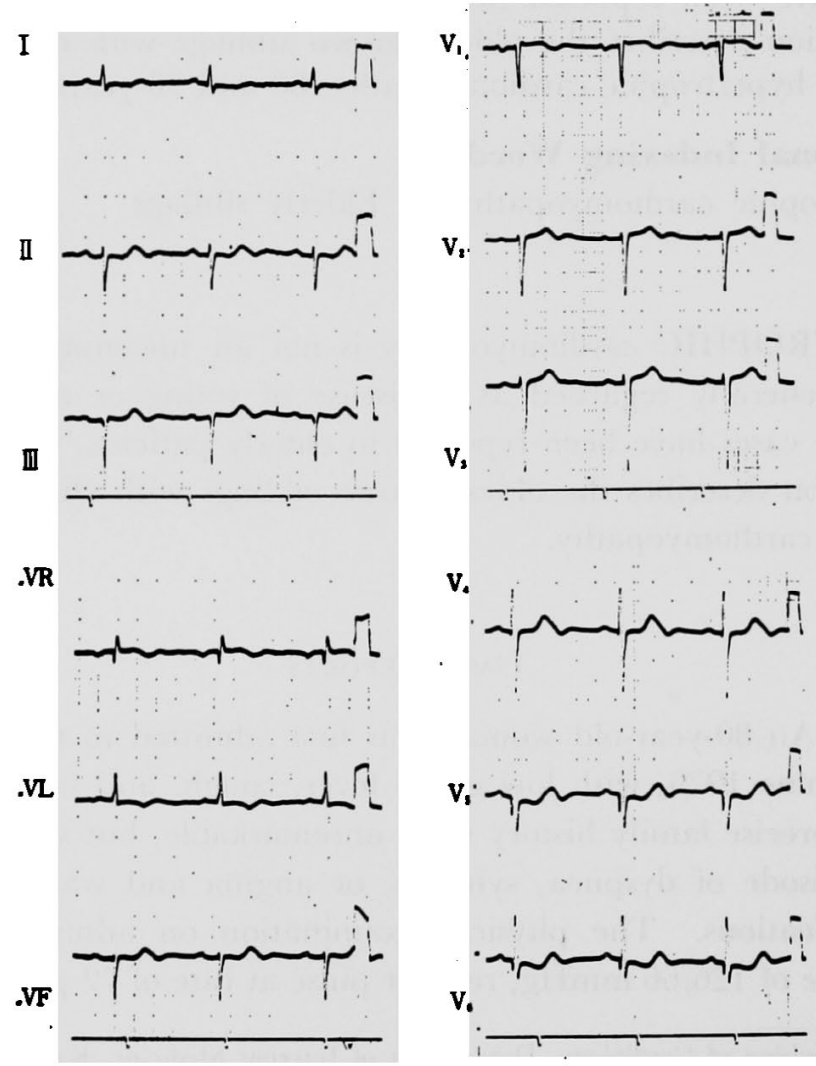

Fig. 2. Electrocardiogram of Case 1 shows left axis deviation and prominent $Q$ wave in lead $V_{5}$ and $V_{8}$. 


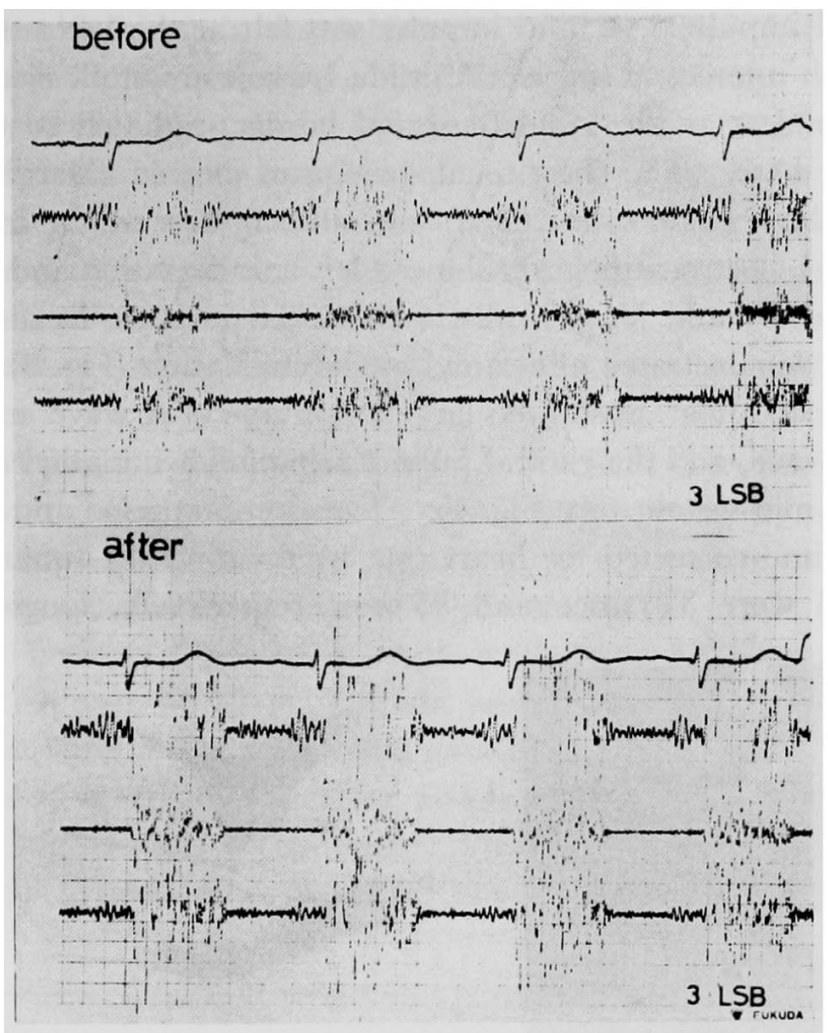

Fig. 3. Phonocardiogram before and after inhalation of amyl nitrite in Gase 1. A marked increase in the intensity of murmur is demonstrated after amyl nitrite inhalation.

\section{before after}

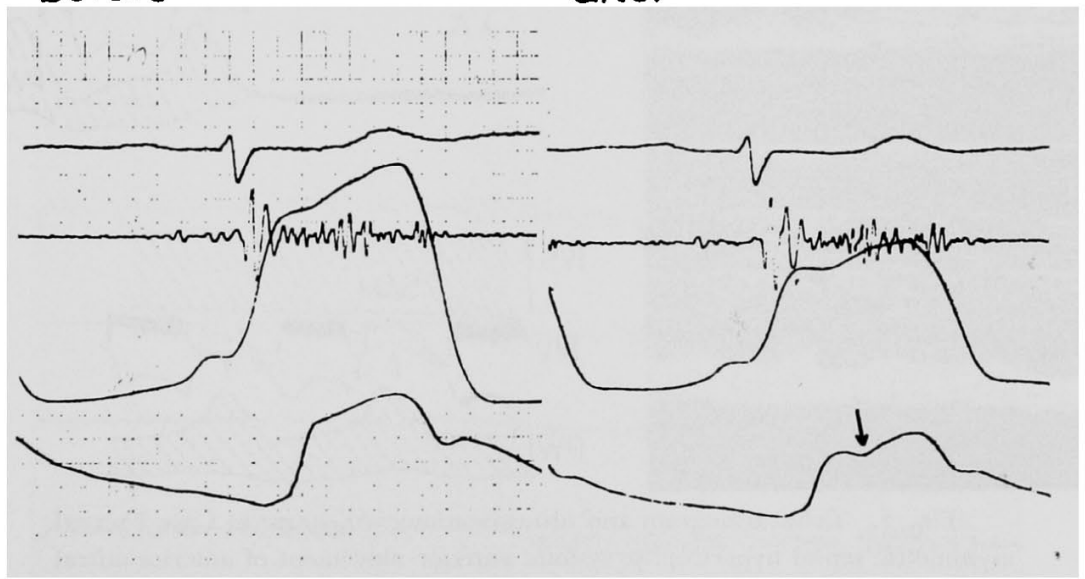

Fig. 4. Apexcardiogram and carotid pulse tracing before and after amyl nitrite inhalation in Case 1. A large A wave amplitude, diminished rapid filling wave and mid-systolic dip of carotid pulse tracing after amyl nitrite inhalation (indicated by arrow) are shown. 
rising carotid impulse. A bifid impulse was felt at the left anterior axillary line in the 5th intercostal space. A grade $4 / 6$ coarse systolic ejection murmur was heard loudest at the low left sternal border, radiated to the apex and faintly to the base. The chest roentogenogram showed enlarged cardiac silhouette (cardiothoracic ratio: 63\%) and an infiltrate in the left lower lobe (Fig. 1). The electrocardiogram showed left axis deviation and prominent $Q$ waves in lead $V_{5}$ and $V_{6}$ (Fig. 2). A marked increase in intensity of the murmur was demonstrated after amyl nitrite inhalation (Fig. 3).

The apexcardiogram showed large amplitude of $\mathrm{A}$ wave and diminished rapid filling wave, and the carotid pulse tracing following amyl nitrite inhalation revealed mid-systolic dip (Fig. 4). The ejection period and isovolumetric contraction time corrected for heart rate by dividing the square root of the R-R interval were $330 \mathrm{msec}$ and $95 \mathrm{msec}$ respectively, longer than those
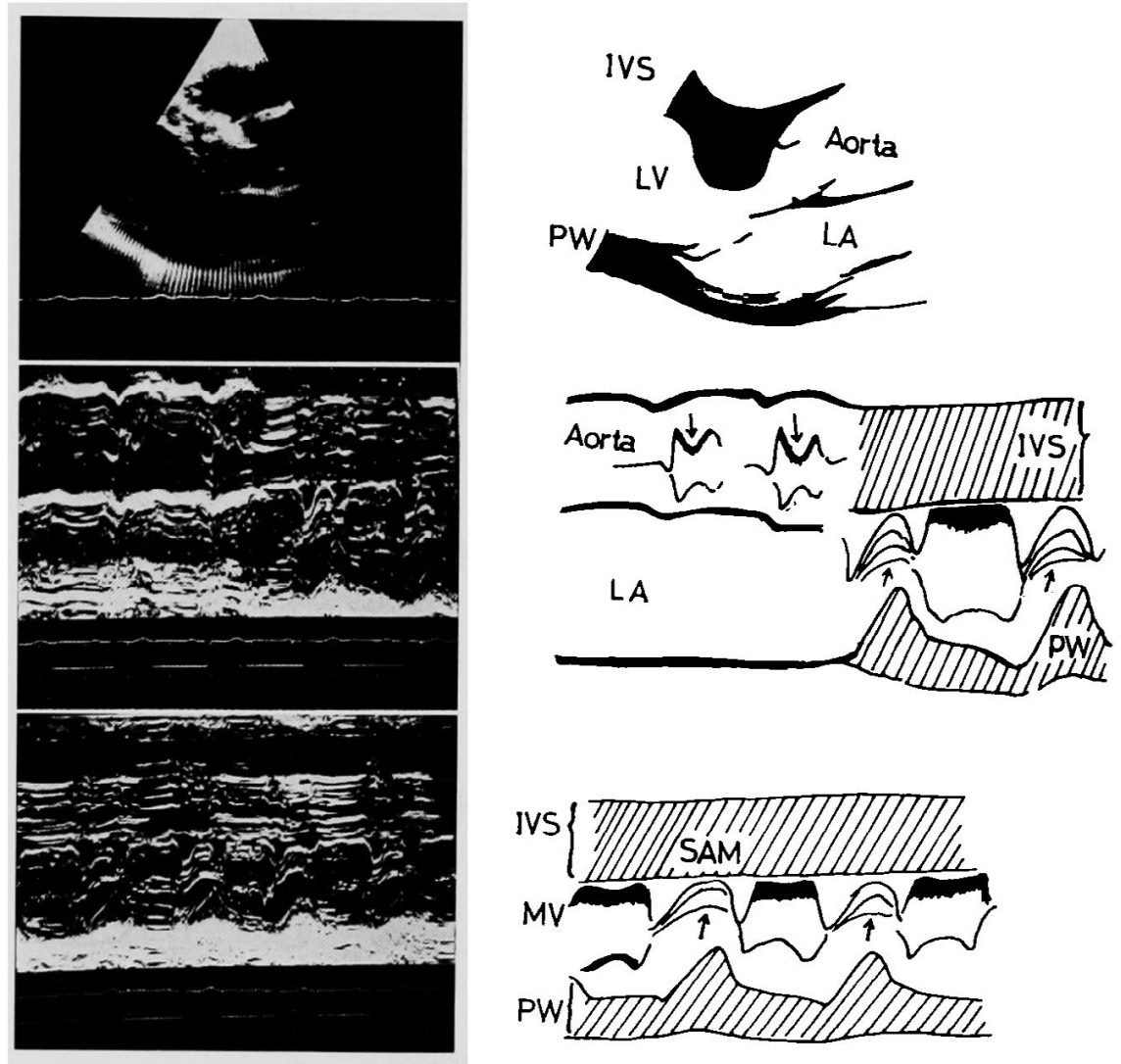

Fig. 5. Echocardiogram and ultrasonotomocardiogram in Case 1 reveal asymmetric septal hypertrophy, systolic anterior movement of anterior mitral valve and partial mid-systolic closure of aortic valve (indicated by arrow). Abbreviation: IVS = inter-ventricular septum; $\mathrm{PW}=$ left ventricular posterior wall; $L V=$ left ventricle; $L A=$ left atrium; $S A M=$ systolic anterior movement of anterior mitral valve; $\mathrm{MV}=$ mitral valve. 
found in normal subjects in our laboratory. ${ }^{91}$ The echocardiogram showed marked asymmetric hypertrophy of inter-ventricular septum, small left ventricular cavity (Dd: $3.8 \mathrm{~cm}$, Ds: $2.0 \mathrm{~cm}$ ), systolic anterior motion and slowing of the early diastolic closing motion of the anterior mitral valve.

The aortic valve echogram showed mid-systolic partial closure (Fig. 5). The thickness of inter-ventricular septum and the postero-basal region of free wall at end-diastole were $2.6 \mathrm{~cm}$ and $1.1 \mathrm{~cm}$ respectively. Two-dimensional echocardiogram revealed disproportionate thickening of the inter-ventricular septum (Fig. 5).

Case 2; A 78-year-old sister of Case 1 was admitted to the Inami-Kousei Hospital in April 1979, with epigastric pain. Her past history was uncertain, but she had never experienced dyspnea, angina, or syncope and never been under medical care elsewhere before this admission.

Physical findings disclosed a blood pressure of $122 / 70 \mathrm{mmHg}$, the irregular pulse at rate of 72 per minute and the brisk-rising carotid pulse. The chest was clear. The heart was enlarged with double apical impulse. A grade 2/6 systolic ejection murmur and faint diastolic murmur were heard loudest at the higher right sternal border (Fig. 6). Electrocardiogram showed left ventricular hypertrophy (Fig. 7). The chest roentogenogram (Fig. 8)

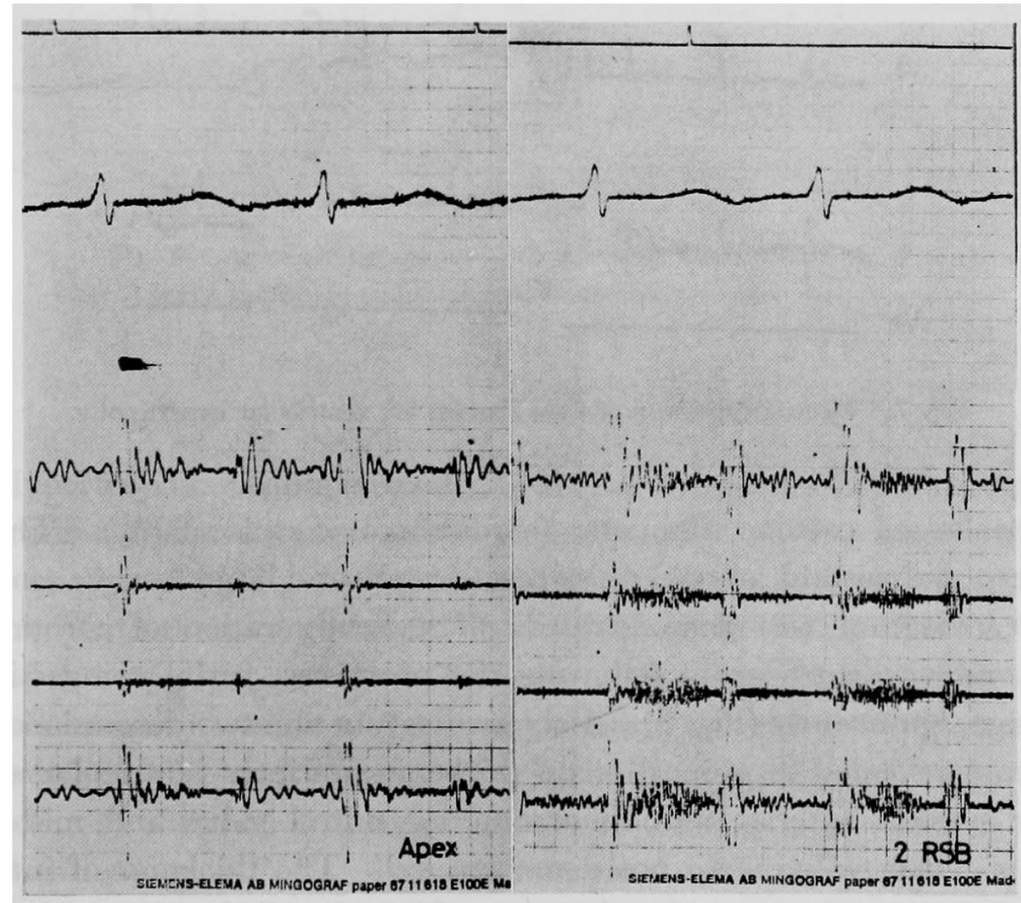

Fig. 6. Phonocardiogram in Case 2 shows systolic ejection murmur at the higher right sternal border. 


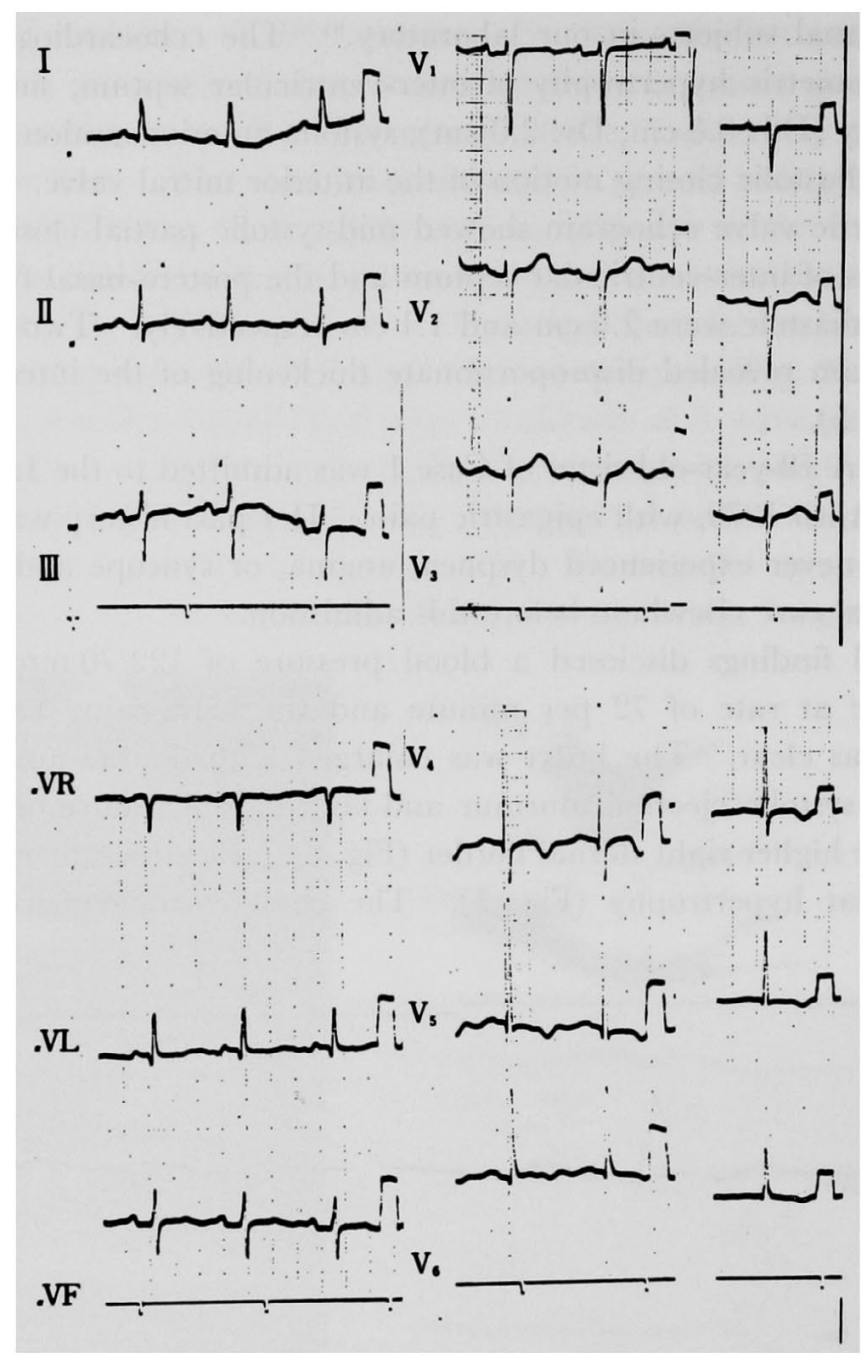

Fig. 7. Electrocardiogram of Case 2 shows left ventricular hypertrophy.

showed enlarged cardiac silhouette (cardiothoracic ratio: 60\%). The indirectly recorded carotid arterial pulse rose sharply and large A wave amplitude of apexcardiogram was demonstrated. The configuration of carotid pulse tracing and apexcardiogram following the premature atrial contraction did not change significantly (Fig. 9). Echocardiogram and two-dimensional echocardiogram revealed disproportionate thickening of inter-ventricular septum, however systolic anterior motion of anterior mitral valve and mid-systolic closure of aortic valve were not demonstrated. The thickness of inter-ventricular septum and postero-basal region of left ventricular free wall at enddiastole was $2.6 \mathrm{~cm}$ and $1.0 \mathrm{~cm}$ respectively (Fig. 10). 


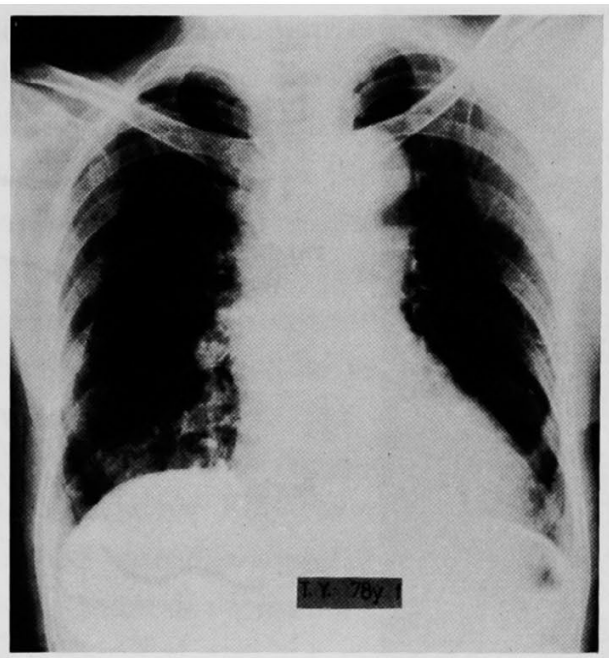

Fig. 8. Chest roentogenogram of Case 2 shows enlarged cardiac silhouette (cardiothoracic ratio: 60\%).

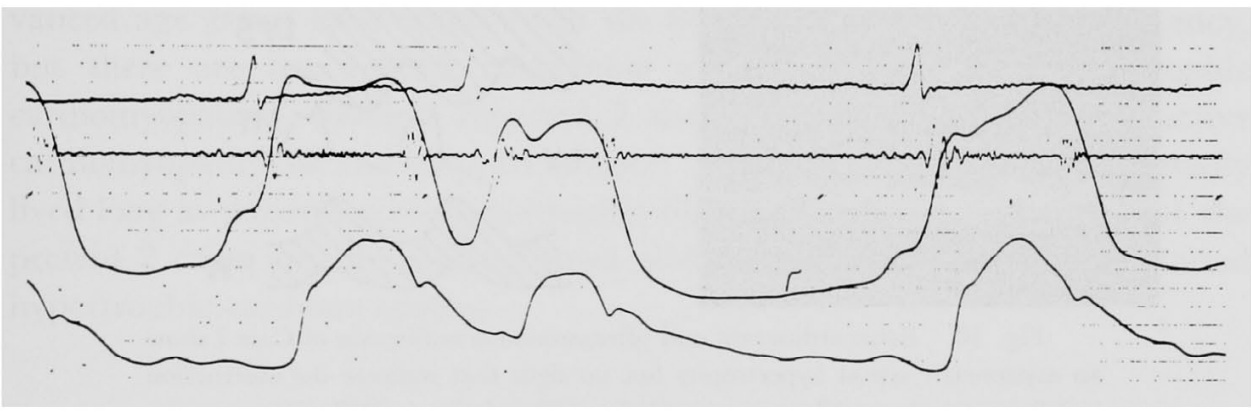

Fig. 9. Apexcardiogram and carotid pulse tracing of Case 2 show a large A wave amplitude and diminished rapid filling wave.

\section{Discussion}

Hypertrophic cardiomyopathy, which is sometimes familial and genetically transmitted as an autosomal dominant trait, ${ }^{10-12)}$ is a disease of cardiac muscle characterized by disproportionately thickened interventricular septum compared with the postero-basal left ventricular free wall.10),12)-15) Although some of these patients have obstruction to left ventricular outflow tract due to systolic anterior motion of the anterior mitral valve ${ }^{10), 13), 16)-18)}$ or markedly hypertrophied and vigorously contracting ventricular septum, ${ }^{19)}$ the presence or absence of obstruction to ventricular outflow may not represent a fundamental difference. ${ }^{101,13), 14)}$ The hypertrophic cardiomyopathy in young or middle-aged patients is easily diagnosed, but that in aged patients frequently missed because of the similarity or coexistence of coronary artery disease or 

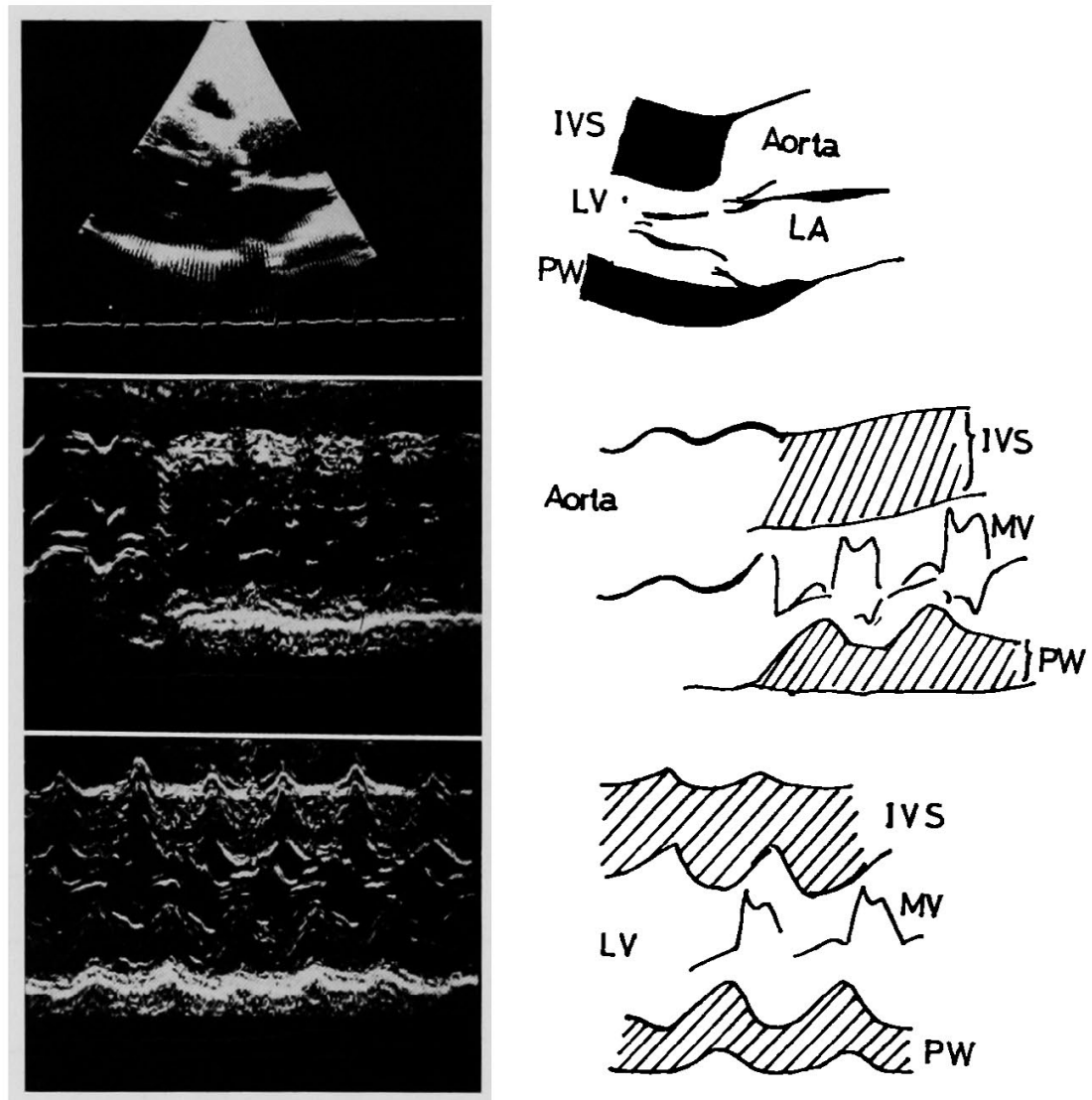

Fig. 10. Echocardiogram and ultrasonotomocardiogram of Case 2 show an asymmetric septal hypertrophy but no signs that indicate the obstruction to left ventricular outflow are revealed. Abbreviation: IVS $=$ inter-ventricular septum; $L V=$ left ventricle; $L A=$ left atrium; $M V=$ mitral valve; $P W=$ left ventricular posterior wall.

hypertensive heart disease. ${ }^{51,11), 20)-221}$

However, recent studies using echocardiography have shown a characteristic sign of hypertrophic cardiomyopathy and made it possible to diagnose in elderly patients. The echocardiographic features of hypertrophic cardiomyopathy include asymmetric septal hypertrophy, ${ }^{101,12)-16)}$ anterior displacement of the mitral apparatus, ${ }^{19)}$ systolic anterior movement of mitral valve, 10),16)-19) reduced velocity of early diastolic closing motion of anterior mitral leaflet, ${ }^{14)}$ inter-ventricular septal hypokinesia, ${ }^{23)}$ and mid-systolic closure of the aortic valve. ${ }^{24)}$ Though the cardiac catheterization and left ventriculography were not performed in our 2 cases, the characteristic echocardiographic features consisting of systolic anterior motion of anterior mitral valve, midsystolic closure of aortic valve in Case 1 and asymmetric septal hypertrophy of Case 1 and Case 2 confirmed the diagnosis of hypertrophic cardiomyo- 
pathy. The systolic anterior movement of anterior mitral valve, mid-systolic closure of aortic valve, mid-systolic dip of carotid pulse tracing following the amyl nitrite inhalation and prolonged left ventricular ejection time index and isovolumetric contraction time index in Case 1 strongly suggested the presence of left ventricular outflow tract obstruction in this case.

In Case 2, asymmetric septal hypertrophy was shown by echocardiogram, but there were no signs that suggested the obstruction to left ventricular outflow tract. The etiology of diastolic murmur observed in Case 2 was uncertain, but Frank reported that this type of murmur was present in 7 of 126 patients ${ }^{111}$ and Hara reported early diastolic murmur of unknown etiology in 1 of 5 patients with idiopathic hypertrophic cardiomyopathy. ${ }^{25)}$ Although the cause of hypertrophic cardiomyopathy is still unknown, the occurence of obstructive and non-obstructive cardiomyopathies in two elderly siblings suggest that the disease is familial and the presence or absence of obstruction is merely a different manifestation of the same basic cardiac disease. ${ }^{101,12)-14,26 \text { ) }}$

In recent years, the reports of hypertrophic cardiomyopathy in the advanced age group have appeared in the literature with increasing frequency, but there are few reports concerning elderly siblings with hypertrophic cardiomyopathy. Sanders reported 2 sisters with hypertrophic obstructive cardiomyopathy, 68 and 63 years of age. ${ }^{1)}$ These 2 cases in siblings unusually lived long as patients with hypertrophic obstructive cardiomyopathy, but the present 2 cases are the oldest known siblings with clinically demonstrated hypertrophic cardiomyopathy.

\section{REFERENCES}

1. Sanders CA, Ansten WG, Jordan JC, Scannell JG: Idiopathic hypertrophic subaortic stenosis in two elderly siblings. New Engl J Med 274: 1254, 1966

2. Ewy GA, Marcus FI, Bohajalian O, Burke H, Roberts WG: Muscular subaortic stenosis, clinical and pathologic observations in an elderly patients. Am J Cardiol 22: 126, 1968

3. Whiting RB, Powell WJ Jr, Dinsmore RE, Sanders CA: Idiopathic hypertrophic subaortic stenosis in the elderly. New Engl J Med 285: 196, 1971

4. Albin EL, Chandraratna PAN, Littman BB, Lopez JM, Samet P: Idiopathic hypertrophic subaortic stenosis in the elderly. Am J Med Sci 274: 163, 1977

5. Hamby WL, Aintablian A: Idiopathic hypertrophic subaortic stenosis in the septuagevarian. Clin Res 24: 220A, 1976

6. Krasnow N, Stein RA: Hypertrophic cardiomyopathy in the aged. Am Heart J 96: 326, 1978

7. Hirai A, Rikitake T, Masuda Y: Idiopathic hypertrophic subaortic stenosis: report of 3 cases of old age. Cardiovasc Sound Bull 3: 429, 1973

8. Sawayama T, Tsuda T, Mizutani K: Diagnostic value of carotid arterial pulse of hypertrophic cardiomyopathy seen in the elderly. Respiration and Circulation 28: 909, 1980 (in Japanese)

9. Hara S, Masuya K, Matsui S, Maeda M, Takeuchi N, Hiramaru Y, Takekoshi N, Murakami E: Mechanocardiographic observation of idiopathic hypertrophic subaortic stenosis (IHSS). 
Cardiovasc Sound Bull 3: 107, 1973

10. Epstein SE, Henry WL, Clark CE, Roberts WC, Maron BJ, Ferrans VJ, Redwood DR, Morrow AG: Asymmetric septal hypertrophy. Ann Intern Med 81 : 650, 1974

11. Frank S, Braunwald E: Idiopathic hypertrophic subaortic stenosis, clinical analysis of 126 patients with emphasis of the natural history. Circulation 37: 759, 1968

12. Clark CE, Henry WL, Epstein SE: Familial prevalance and genetic transmission of idiopathic hypertrophic subaortic stenosis. New Engl J Med 289: 709, 1973

13. Henry WL, Clark CE, Epstein SE: Asymmetric septal hypertrophy, echocardiographic identification of the pathognomonic anatomic abnormality of IHSS. Circulation 47:225, 1973

14. Abbasi AS, MacAlpin RN, Eber LM, Pearce ML: Echocardiographic diagnosis of idiopathic hypertrophic cardiomyopathy without outflow obstruction. Circulation 46: 897, 1972

15. Shah PM. Gramiak R, Hramer DH: Ultrasound localization of left ventricular outflow obstruction in hypertrophic cardiomyopathy. Circulation 40:3, 1969

16. Popp RL, Harrison DC: Ultrasound in the diagnosis and evaluation of therapy of idiopathic hypertrophic subaortic stenosis. Circulation 40: 905, 1969

17. Henry WL, Clark CE, Glancy L, Epstein SE: Echocardiographic measurement of the left ventricular outflow gradient in idiopathic hypertrophic subaortic stenosis. New Engl J Med 288: 989, 1973

18. Rodger JC: Motion of mitral apparatus in hypertrophic cardiomyopathy with obstruction. Brit Heart J 38: 732, 1976

19. Henry WL, C:lark C:E, Griffith JM, Epstein SE: Mechanism of left ventricular outflow obstruction in patients with obstructive asymmetric septal hypertrophy (Idiopathic hypertrophic subaortic stenosis). Am J Cardiol 35: 337, 1975

20. Prescott R, Quinn JS, Littman D: Electrocardiographic changes in hypertrophic subaortic stenosis which simulate myocardial infarction. Am Heart J 66: 42, 1963

21. Peter RH, Gracey JG, Beach TB: Subaortic stenosis simulating coronary disease, report of two patients presenting problems in differential diagnosis. Arch Intern Med 121:564, 1968

22. Lardani H, Serrano JA, Villamil RJ: Hemodynamics and coronary angiography in idiopathic hypertrophic subaortic stenosis. Am J Cardiol 41: 476, 1978

23. Rossen RM, Goodman DJ, Ingham RE, Popp R: Ventricular systolic septal thickening and excursion in idiophthic hypertrophic subaortic stenosis. New Engl J Med 291 : 1317, 1974

24. Chahine RA, Raizner AE, Nelson J, Winter WL Jr, Miller RR, Luchi RJ: Mid systolic closure of aortic valve in hypertrophic cardiomyopathy. Am J Cardiol 43: 17, 1979

25. Hara S, Masuya K, Matsui S, Maeda M, Takeuchi N, Kin T, Onoe T, Tsuchiya M, Takekoshi N, Murakami E: Phonocardiographic observation of idiopathic hypertrophic subaortic stenosis (IHSS). Cardiovasc Sound Bull 2: 311, 1972

26. Nasser WK, Williams JF, Mishkin ME, Childress RH, Helmen C, Merritt AD, Genovese PD: Familial myocardial disease with and without obstruction to left ventricular outflow, clinical, hemodynamic and angiographic findings. Circulation 35: 638, 1967 